\title{
Many doctors feel "betrayed" by sale of MD Financial Management
}

\author{
Cite as: CMAJ 2018 June 25;190:E776-7. doi: 10.1503/cmaj.109-5619
}

Posted on cmajnews.com on June 5, 2018.

W hen the Canadian Medical Association (CMA) announced on May 31 that it was selling its financial services company, MD Financial Management, to Scotiabank for almost $\$ 2.6$ billion, the reaction from physicians was swift and brutal.

MD clients and other CMA members took to social media to condemn the decision, complaining that they had not been consulted on the sale and voicing concern that MD's reputation as a company focused on the needs of physicians first and foremost would be lost. Dozens of messages on Twitter and Facebook accused the CMA of failing its members.

"Immensely disappointed in CMA's shortsighted sale of MD Management to Scotiabank. This could not possibly be more against the interest of physicians, and with no prior consultation or transparency," read one typical response. "We may watch CMA membership dwindle to that of the AMA [American Medical Association] over this."

"I feel betrayed," said Dr. Rob Suppes, an emergency physician from Sault Ste. Marie, Ontario. "The sale to Scotiabank removes [MD's] benefit for me as a company."

Suppes said he is disappointed because although MD wasn't a nonprofit, it presented itself as having the best interests of doctors at heart, while big banks seemed more focused on their own profits. "You trust them; they've got this reputation of being very good for physicians, and then they do something like this and you realize, well, I'm just a client," he said. "The benefit for me from MD was I didn't feel like just a client. It touts itself as a company that understands the needs of doctors, set up to help us with our financial management without necessarily trying to sell us anything."

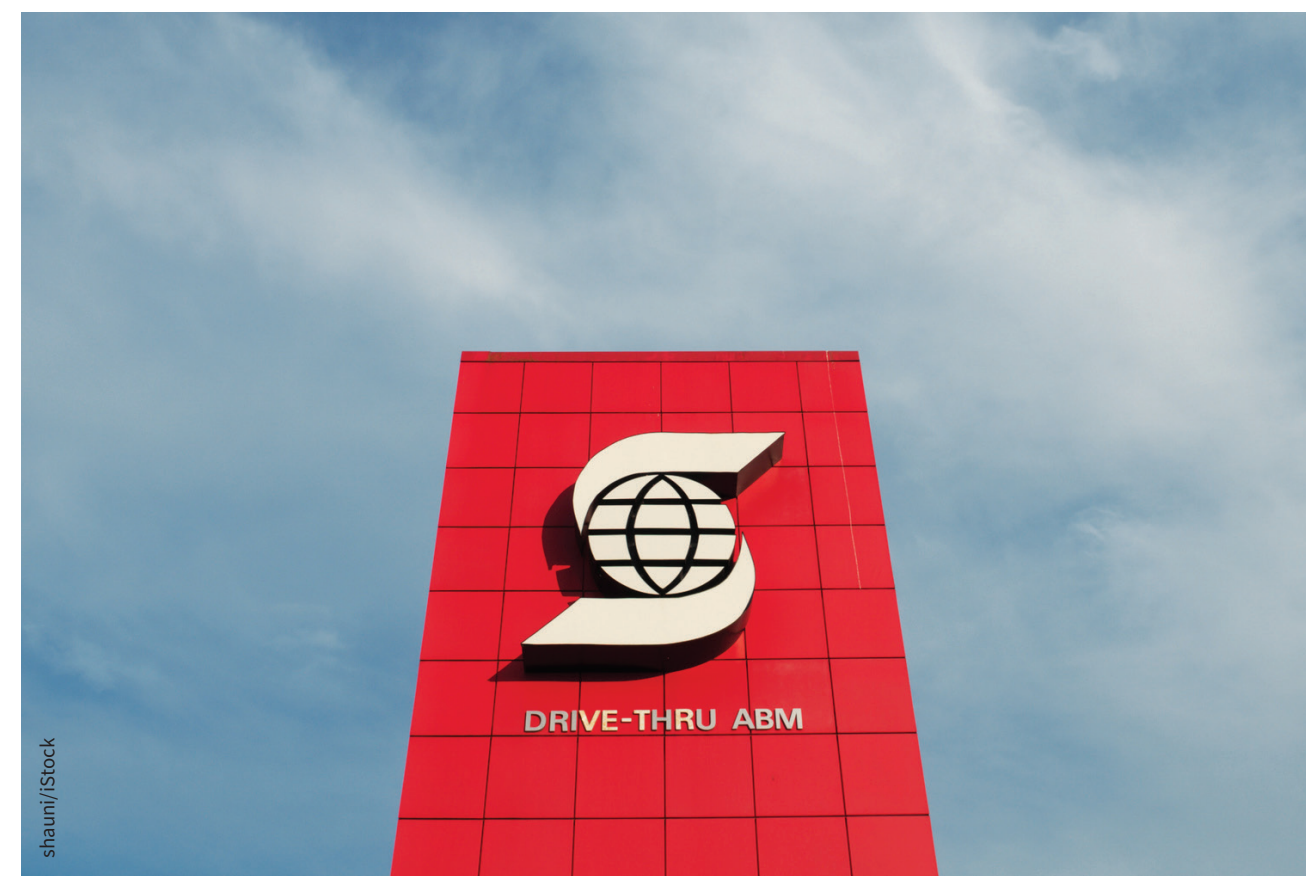

Many CMA members expressed surprise and dismay over the sale of MD Financial to Scotiabank.

Dr. Paul Healey, an emergency doctor in Oakville, Ontario, runs the Physician Financial Independence discussion group on Facebook. He said his group's 6000 members reacted almost uniformly negatively to the news of the sale. Though many of the group's members had already left MD to manage their own investments, a large number are still with the company and are furious they were not consulted, and that their personal financial information may now become property of another company. He thinks this will be a watershed moment that causes a lot of doctors to take a closer look at how they manage their finances.

"It's forcing some people to face some realities about MD that they never really faced before," he said. "The marketing has always been that it was owned by physicians, for physicians. But it was never nonprofit, though the marketing may have led a lot of physicians to make that conclusion."

Dr. Brian Brodie, chairman of the CMA Board of Directors, said the sale of MD fits within the association's new strategy, the CMA 2020 Vision. "It's going to offer new opportunities to support a vibrant profession and a healthy population," he said. "The existing and future MD clients are going to benefit from an expanding scope of services at competitive terms and pricing, with enhanced technology-enabled options and responsiveness to their needs."

The CMA will set up a separate board to serve as its investment arm to administer the $\$ 2.6$ billion. There are no details yet on how the money will be spent, but Brodie said it would be used to advance 
the association's core advocacy role. Also, membership fees will be reduced to $\$ 195$ per year and eliminated for retirees, residents and medical students.

In addition, Scotiabank has committed to a \$115 million, 10-year partnership with CMA in support of the association's advocacy goals. The first $\$ 15$ million has been earmarked for a potential new building dedicated to health care innovation, with another $\$ 10$ million per year to support advocacy, sponsor meetings and support research chairs and scholarships. "The money will be directed towards improving health care in Canada," said Brodie.

The biggest complaint has been the lack of transparency around the decision to sell. A statement from MD said that the negotiations with Scotiabank, a publicly traded company, had to be kept confidential to comply with rules around the disclosure of information to the markets. But many CMA members have asked why they were not consulted on the initial decision to put the company up for sale.

"I can only say that an open and transparent conversation about the propriety of selling MD would have been incredibly destabilising and disruptive to the employees and clients of MD," said Brodie. Grassroots members cannot be expected to be kept up to date on all the complexities of a company operating in the financial markets. "This is not something to have a public poll on; this is something to have a very clear line of sight by a board overseeing a company that is managing the resources of Canadian doctors."

Brodie said the sale of MD will be a seamless transition for clients. "Scotiabank is committed to maintaining MD's brand and its unique physician-specific service model, as well as retaining the expertise of the MD team," he said.

Despite these assurances from the CMA board, the reaction on social media suggests that many members are considering leaving both MD and the CMA because of the sale. Healey said that many doctors considered MD the biggest benefit of being a member of the CMA. Without it, "what is the utility of CMA membership?" he said.

One financial planner, who asked to remain anonymous, said he expects it will now become easier for him to pick up physician clients. "From my experience prospecting medical professionals, they're often very loyal to MD because MD is perceived as a nonprofit, being owned by the CMA. I wonder how loyal they are to Scotiabank," he said.

Suppes is one who may leave both MD and the CMA. "MD was the only reason I'm part of CMA," he said. "If you take it out of the picture, I have zero reason to be a member of the association."

Brian Owens, St. Stephen, NB 